\title{
A national support service
}

The Royal College of Physicians' (RCP's) publication Work and wellbeing in the NHS: why staff health matters to patient care ${ }^{1}$ summarises the current poor performance of the service in these matters. Sickness absence rates, a key metric reflecting morale, are $27 \%$ higher than the average for UK public services, and a shocking $46 \%$ above the UK average overall. Poor mental health underlies more than a quarter of the absences, and self-reported stress affects nearly one in four NHS employees in England. The morale of staff appears to correlate with job satisfaction and perceptions of whether individuals are valued by their employers, and there appears to be a huge variation between different NHS organisations. These issues are important, as staff health is reflected in the quality of patient care that can be provided, from reasons as varied as a lower MRSA transmission rate when staff morale is higher, to greater locum costs when staff are on sick leave. Staff in all grades doctors, nurses, paramedics and support staff - are all prone to work-related illness, reflecting in large part their working conditions.

The RCP's publication outlines areas for action, of which the first is that trusts and commissioners should prioritise staff engagement and wellbeing. Other recent publications have emphasised another of the action points - support for clinicians to help manage psychological stress following adverse clinical incidents and during fitness-to-practice investigations. Harrison et al ${ }^{2}$ emphasised in this journal the professional and personal impact of adverse events on doctors, with the majority suffering stress, anxiety, sleep disturbance and a loss of professional self-confidence; probably a quarter of the doctors surveyed showed manifestations of post-traumatic stress disorder. However, nearly half the doctors surveyed (well over $1,000)$ rated the results of reporting the incident as inadequate, and indeed many incidents went unreported.

More headlines resulted from an independent review commissioned by the General Medical Council (GMC) on doctors who committed suicide while under GMC fitnessto-practice investigation -28 in all over eight years. ${ }^{3}$ During this period, 114 doctors had died with an open and disclosed GMC case at the time of death, and thus the $28 / 114$ proportion is truly shocking - although it must be clear that this is very far from being a cause-and-effect relationship. The issues that underlie many fitness-to-practice investigations, such as mental health, alcoholism and drug addiction, carry with them a suicide risk, and in many surveys, doctors as a whole carry a greater suicide risk than the general population, with depression and work-related stress a common background. ${ }^{4}$ Nonetheless, the review highlighted the vulnerability of doctors under investigation. Most of the recommendations of the report (produced by Sarndrah Horsfall, previously chief executive of the National Patient Safety Agency) concern current GMC practice, for example the first recommendation is that doctors under investigation should feel they are treated as 'innocent until proven guilty'. More far reaching is the recommendation for the establishment of a National Support Service (NSS) for doctors.

The NSS would be a national body to assume responsibility for day-to-day management of doctors with health concerns, incorporating assessment, management, treatment, education and prevention. ${ }^{3}$ The range of reasons for referral would be wide, ranging from mental health problems to addiction and drug abuse. Doctors, and indeed medical students, could self-refer in confidence, but colleagues, employers and the GMC could also refer. (The latter could provide a means to attempt to safeguard and support doctors undergoing disciplinary procedures.) The NSS would provide a medical supervisor for the doctor, coordinate and monitor an agreed treatment plan, and also assess whether the doctor's condition is putting patients at risk. The NSS is envisaged as operating independently from the GMC, but remaining under the GMC's authority. There would be an agreed process for referral to the GMC if issues of probity, illegal or very serious behaviours were involved, and for discussing with the regulator whether patient safety concerns merit short-term conditions being placed on registration.

A model for this has existed in London for some years - the Practitioner Health Programme (PHP). ${ }^{5}$ Set up in 2008, PHP is a confidential, NHS treatment service for doctors and dentists who are unable to access confidential care through mainstream NHS routes due to the nature of their role and/ or health condition. To date, the service has been accessed by approximately 250 doctors and dentists yearly. Its results for maintaining in/return to work are impressive. Disappointingly,

\begin{tabular}{|c|c|}
\hline \multicolumn{2}{|c|}{ Members of the editorial board } \\
\hline $\begin{array}{l}\text { Professor Humphrey Hodgson } \\
\text { Editor }\end{array}$ & $\begin{array}{l}\text { Dr Cordelia Coltart } \\
\text { International edito }\end{array}$ \\
\hline $\begin{array}{l}\text { Dr Paul Grant } \\
\text { Editorial registrar }\end{array}$ & $\begin{array}{l}\text { Cono Ariti } \\
\text { Statistical editor }\end{array}$ \\
\hline
\end{tabular}

Dr Na'eem Ahmed Paul Belcher

Dr Rodger Charlton

Dr Tahseen Chowdhury

Nick Cork

Dr Kate Evans

Professor Brian Hurwitz
Dr Angela King Professor Martin McKee Dr Mehool Patel Dr Roby Rakhit Dr Ian Starke Dr Kevin Stewart Professor Cameron Swift 
the top line of its website (accessed March 2015) states 'PLEASE NOTE: We are sorry that we are unable to accept new referrals for London residents at this time due to unprecedented demand for services' ${ }^{5}$ - ie lack of resources.

Which brings in the issue of finance. The London PHP is financed by approximately $£ 1.2$ million yearly from the London Specialised Commissioning Group. The GMC's review suggests a nationwide annual price tag of approximately $\mathfrak{E} 6$ million for the service and speculates on where that might be raised, recommending national support (Department of Health, NHS England and the devolved administrations) for two years to set up the scheme, and subsequent funding from the GMC by a potential $5 \%$ increase in the annual retention fee or possibly from existing GMC income. ${ }^{3}$ Strong reactions may be anticipated to some of these suggestions, but should not prevent the development of a service which will not only help doctors but, judging from the success of the London project, help protect the quality of care they provide.

\section{References}

1 RCP. Work and wellbeing in the NHS: why staff health matters to patient care. London: RCP, 2015.

2 Harrison R, Lawton R, Stewart K. Doctors 'experiences of adverse events in secondary care: the professional and personal impact. Clin Med 2014;14:585-90.

3 Horsfall S. Doctors who commit suicide while under GMC fitness to practise investigation: Internal review. London: General Medical Council, 2014.

4 Meltzer H, Griffi ths C, Brock A et al. Patterns of suicide by occupation in England and Wales: 2001-2005. Br J Psychiatry 2008;193:73-6.

5 Practitioner Health Programme. NHS practitioner Health Programme. Available online at http://php.nhs.uk/ [Accessed 25 March 2015].

6 Practitioner Health Programme. PHP Annual Reports. Available online at http://php.nhs.uk/resources/php-annual-reports/ [Accessed 25 March 2015].

Humphrey Hodgson

\title{
Registration at the time of graduation
}

\author{
Author: Peter Kopelman ${ }^{\mathrm{A}}$
}

The point at which the General Medical Council (GMC) grants registration to newly qualified doctors has been debated for some while. At the heart of this is patient safety.

In 1968, the Royal Commission on Medical Education endorsed the approach of the Goodenough Committee, twenty years earlier, which expressed concern about the experience and clinical competence of newly graduated doctors and advocated a supervised preregistration year after graduation from medical school. ${ }^{1,2}$ The preregistration year is now incorporated as the first year of Foundation Programme (FY1) and is regarded as a key component of the start of postgraduate medical training in the UK.

The expansion of medical student numbers and medical schools in England have raised concerns about the prospect of medical graduates finding themselves both unemployed and unemployable if they fail to secure a FY1 post. At first sight moving GMC full registration to the time of graduation would overcome this. ${ }^{3}$ It would additionally address the question of who actually has oversight of doctors in the first year of the Foundation Programme by enabling those overseeing postgraduate medical education to take full responsibility rather than sharing this with medical schools whose graduate may be working in a distant part of the UK. Changing the timing furthermore will potentially provide UK Health Services with a greater opportunity to regulate the numbers of doctors they wish to fund and train at any one time. But this would not address the risks of medical unemployment among those just qualified because the

Author: Aprincipal, St George's, University of London, London, UK competition for FY1 places may significantly increase. Moving the timing of registration will open eligibility to the Foundation Programme for all newly registered doctors in Europe rather than the current limitation to those countries that have comparable schemes of internship.

The Medical Schools Council has welcomed the announcement by the undersecretary for health of a 'stakeholder engagement period' on moving the point of registration but acknowledges that 'such a move raises complex issues that will need to be addressed during the proposed engagement process'. ${ }^{4}$

The four most pressing issues to my mind are: preparedness of graduates for clinical practice; practical prescribing abilities of a new graduate; the alignment with the Professional and Linguistic Assessments Board (PLAB) examination or any future national qualifying examination; and the compliance of UK graduate entry to medicine with EU law.

Medical students are undoubtedly better prepared for clinical practice today than in the past. However, the opportunities for practical rather than simulated experience of responsibility and management of patient care are restricted as a medical student. The GMC appropriately considers that the majority of invasive investigative and therapeutic interventions should await qualification. This understandably results in newly qualified doctors expressing a concern about how well they feel prepared for the practical elements and responsibilities of a FY1 doctor. Such concern varies between students from different medical schools and is unrelated to how closely they consider that they are supervised in clinical settings. ${ }^{5-9}$

A number of recent studies (most notably the GMC's EQUIP study) have raised questions about errors in prescribing by 